ORIGINAL ARTICLE

\title{
Nighttime driving, passenger transport, and injury crash rates of young drivers
}

\author{
T M Rice, C Peek-Asa, J F Kraus
}

Injury Prevention 2003;9:245-250

See end of article for authors' affiliations

\section{Correspondence to:} Mr Thomas M Rice, Southern California Injury Prevention Research Center, University of California, Los Angeles, School of Public Health, 10911 Weyburn Avenue, Suite 200, Los Angeles, CA 90024, USA;

tr@ucla.edu

\begin{abstract}
Objective: This study examines the association of nighttime driving and the carrying of passengers with the rate of motor vehicle crashes that resulted in severe or fatal injury to young drivers in California before the implementation of a graduated licensing system.

Method: Passenger vehicle drivers aged 16 or 17 involved in injury crashes in California from 1 January 1993 to 30 June 1998 were identified through a police crash database. An induced exposure method was used to estimate driving exposure. Odds ratios for driver injury crashes were estimated with logistic regression.

Results: Driving at night, driving without adult supervision, driving with passengers, using alcohol, being 16, and being male were associated with high rates of driver injury crash.

Conclusions: The injury crash rate for drivers aged 16 or 17 increases during nighttime hours and in the absence of adult supervision, with or without other passengers. Driving between $10 \mathrm{pm}$ and midnight is particularly dangerous for young drivers. Nighttime driving restrictions that begin at $10 \mathrm{pm}$ or earlier and restrictions on carrying passengers at any hour may increase the effectiveness of graduated licensing systems.
\end{abstract}

listis has long been known that teenage drivers have higher crash rates than adult drivers. Because young drivers lack maturity and driving experience, they are less able to identify hazards, ${ }^{12}$ and are more likely to exhibit risky driving behaviors-for example, speeding ${ }^{3}$ and following too closely. ${ }^{4}$ One approach to helping young drivers safely gain experience is to limit their driving to conditions that are thought to be low risk. Many US states have done this through the implementation of graduated driver licensing systems. As of April 2003, 39 US states and the District of Columbia had implemented a graduated system for licensing young drivers. ${ }^{5}$ Of these 39 jurisdictions, 20 restrict both nighttime driving and passenger transport, 17 restrict nighttime driving only, and two restrict passenger transport only. The restrictions are generally in effect when teenagers hold learner permits or provisional licenses.

Research has shown that nighttime driving and passenger transport are each associated with increased young driver crash occurrence. ${ }^{6-12}$ While some studies have estimated passenger effects within time categories, ${ }^{811}$ no analysis has simultaneously estimated the independent effects of the two factors.

The objective of this study was to estimate the effects of nighttime driving and passenger carrying on the rate of injury crash. We analyzed data from crashes involving 16 and 17 year old drivers in California during a 5.5 year period before the implementation of the state's graduated licensing system. We used an "induced exposure" method to obtain controls for a case-control study and applied Mantel-Haenszel and maximum likelihood odds ratio methods to estimate rate ratios.

\section{METHODS}

Because we employed a novel use of the induced exposure method, we briefly discuss the theory behind the method before addressing our study findings. A thorough summary of the history and theory of the method is found in Cuthbert, ${ }^{13}$ thus we give only a brief description.

The principal difficulty in conducting studies of crash rates is in obtaining estimates of exposure to the risk of crash.
Because most US states and the federal government have surveillance systems that adequately monitor serious or fatal injury crash involvements, accurate counts for rate numerators are readily available. Obtaining valid estimates of exposure for use as rate denominators is a much greater challenge. The "induced exposure" technique was introduced more than 30 years ago to address this problem. The method was first proposed by Thorpe ${ }^{14}$ and developed further by Carr, ${ }^{15}$ Haight, ${ }^{16}$ and Cuthbert. ${ }^{13}$ Variants of this method have been used in several recent studies. ${ }^{91718}$ The method is based on the premise that culpable drivers that cause two vehicle crashes select their "victims" randomly from all drivers in the area at the time of the crash. The distribution of these non-culpable drivers ("victims") is then compared with that of the group of drivers of interest to produce rate ratios. Various methods for deriving rate ratios have been used.

Case-control studies were developed to overcome the same problem of missing denominators in studies of disease occurrence. Obtaining information from an at-risk population can be difficult, prohibitively expensive, and, in many cases, impossible. A solution to this problem is the use of an exposure distribution of a control group as a substitute for that of the at-risk population. ${ }^{19}$ Early case-control studies conducted in the 1920-50s were simple comparisons of exposure proportions..$^{20}$ Cornfield introduced the odds ratio. ${ }^{21}$ Methods for estimating a common odds ratio and its variance in stratified data were developed by Woolf ${ }^{22}$ and Mantel and Haenszel. ${ }^{23}$ Contemporary case-control analyses generally use Mantel-Haenszel methods or an analogous regression model most often using maximum likelihood estimation. Under certain conditions, odds ratios will approximate "relative risks". ${ }^{24}{ }^{25}$ In the present study, a rare outcome assumption is not required for odds ratios to approximate rate ratios because controls are density sampled throughout the study period.

Abbreviations: ORa, adjusted odds ratio; SWITRS, statewide integrated traffic records system 
Table 1 Characteristic distributions (\%) for cases and controls

\begin{tabular}{|c|c|c|c|}
\hline Characteristic & Value & $\begin{array}{l}\text { Cases } \\
(n=10795)\end{array}$ & $\begin{array}{l}\text { Controls } \\
(n=12906)\end{array}$ \\
\hline \multirow[t]{8}{*}{ Time of crash* } & $6 \mathrm{am}-4 \mathrm{pm}$ & 43 & 50 \\
\hline & $4 \mathrm{pm}-6 \mathrm{pm}$ & 14 & 17 \\
\hline & $6 p m-8 p m$ & 11 & 13 \\
\hline & $8 \mathrm{pm}-10 \mathrm{pm}$ & 9 & 10 \\
\hline & $10 \mathrm{pm}$-midnight & 10 & 6 \\
\hline & Midnight-2 am & 6 & 2 \\
\hline & $2 a m-4 a m$ & 4 & 1 \\
\hline & $4 a m-6$ am & 2 & 0.2 \\
\hline \multirow[t]{7}{*}{ Day of crash } & Mon & 13 & 14 \\
\hline & Tue & 13 & 14 \\
\hline & Wed & 13 & 14 \\
\hline & Thu & 14 & 14 \\
\hline & Fri & 16 & 18 \\
\hline & Sat & 17 & 15 \\
\hline & Sun & 14 & 11 \\
\hline \multirow[t]{2}{*}{ Driver alcohol uset } & No & 90 & 99.7 \\
\hline & Yes & 10 & 0.3 \\
\hline \multirow[t]{2}{*}{ Sexł } & Male & 61 & 51 \\
\hline & Female & 39 & 49 \\
\hline \multirow[t]{2}{*}{ Age } & 16 & 44 & 38 \\
\hline & 17 & 56 & 62 \\
\hline \multirow[t]{4}{*}{ Number of passengers } & None & 48 & 45 \\
\hline & 1 & 29 & 32 \\
\hline & 2 & 12 & 14 \\
\hline & 3 or more & 11 & 9 \\
\hline \multicolumn{4}{|c|}{$\begin{array}{l}\text { *Excluded are } 30 \text { drivers with unknown time of crash. } \\
\text { tExcluded are } 1019 \text { drivers with unknown or unrecorded alcohol use } \\
\text { status. } \\
\text { †Excluded are five drivers with unknown sex. }\end{array}$} \\
\hline
\end{tabular}

\section{Data source}

California law enforcement agencies are required by state law to submit copies of reports for all injury traffic crashes to the California Highway Patrol. We obtained data from the California Highway Patrol statewide integrated traffic records system (SWITRS), a computerized database of crash report information. Submission of reports of non-injury (property damage only) crashes by police departments is voluntary, and thus reporting is likely incomplete and non-representative. To avoid possible bias due to selective reporting, we did not use data from non-injury crashes.

\section{Study design}

We conducted a case-control study using controls identified with an induced exposure method. We initially identified all drivers of passenger vehicles, pick-up trucks, sport utility vehicles, or minivans aged 16 or 17 involved in injury crashes between 1 January 1993 and 30 June 1998. Drivers operating a motorcycle, truck, commercial or farm vehicle, or other nonstandard vehicle (for example, golf cart) or who were towing a trailer were excluded. Cases were visibly injured young drivers in single or multivehicle crashes who were determined by the reporting police office to be culpable. Controls were young drivers in two vehicle injury crashes who were not determined to be culpable and who were not cited for any reason. A total of 10795 cases and 12906 controls were identified.

\section{Study variables}

The analyses included variables in the SWITRS database that describe the crash (day of week, time of day), each vehicle in the crash (driver sex, driver age, injury severity, alcohol use), and occupants in each vehicle (age, sex). Driver injury severity was coded on police crash reports as Fatal, Severe, Visible Injury, Complaint of Pain, or None. Driver alcohol use was determined by the reporting officer as Had Not Been Drinking, Had Been Drinking, or Unknown. For Had Been Drinking, intoxication was further coded as Under Influence, Not Under Influence, and Impairment Unknown. Our driver alcohol use variable was coded positive for any Had Been Drinking level. We did not use the intoxication determination because the use of blood/breath alcohol tests administered differentially by injury severity can produce bias. ${ }^{26}$

\section{Analysis}

Descriptive tabulations of crash and driver characteristics were performed by case status. Logistic regression analysis was used to model the log odds of exposure. The initial model was chosen using prior knowledge. Passenger effect estimates were allowed to vary across levels of alcohol use and time category by including product terms in the models. The degree of heterogeneity was low and was statistically non-significant ( $p$ values from 0.09 to 0.29 ), and model fit was degraded with the terms in the model. Thus the terms were not included in the final model. Sequentially excluded from the final model were drivers with missing information on alcohol use (1019), time of crash (22), sex (5), and passenger age (477). Models were fitted separately for drivers with visible injuries and drivers with severe or fatal injuries. A sensitivity analysis revealed that model coefficients were not meaningfully different when the observations with missing data were included in the model (unadjusted for those variables).

\section{RESULTS}

Twelve percent of case crashes occurred after midnight, compared with 3\% for control crashes (table 1). The distributions of crashes by day of week were similar for cases and controls, although a slightly higher proportion of case crashes

Table 2 Young drivers with injury (cases) and controls, by time of crash and driver sex

\begin{tabular}{|c|c|c|c|c|c|c|c|c|}
\hline \multirow[b]{2}{*}{ Time of crash } & \multicolumn{4}{|c|}{ Male drivers } & \multicolumn{4}{|c|}{ Female drivers } \\
\hline & Cases & Controls & Odds ratio & $95 \% \mathrm{Cl}$ & Cases & Controls & Odds ratio & $95 \% \mathrm{Cl}$ \\
\hline $6: 00 \mathrm{am}-3: 59 \mathrm{pm}$ & 2622 & 3147 & 1 & - & 2058 & 3343 & 1 & - \\
\hline $4: 00 \mathrm{pm}-5: 59 \mathrm{pm}$ & 863 & 1106 & 0.94 & 0.84 to 1.04 & 626 & 1098 & 0.93 & 0.83 to 1.04 \\
\hline $6: 00 \mathrm{pm}-7: 59 \mathrm{pm}$ & 736 & 913 & 0.97 & 0.86 to 1.08 & 492 & 798 & 1.00 & 0.88 tр 1.14 \\
\hline 8:00 pm-9:59 pm & 643 & 672 & 1.15 & 1.02 to 1.30 & 373 & 568 & 1.07 & 0.92 to 1.23 \\
\hline 10:00 pm-midnight & 696 & 437 & 1.92 & 1.67 to 2.18 & 350 & 377 & 1.51 & 1.29 to 1.77 \\
\hline Midnight-1:59 am & 535 & 175 & 3.67 & 3.06 to 4.40 & 161 & 132 & 1.98 & 1.55 to 2.53 \\
\hline $2: 00 \mathrm{am}-3: 59 \mathrm{am}$ & 305 & 61 & 6.00 & 4.52 to 8.07 & 77 & 33 & 3.79 & 2.48 to 5.90 \\
\hline $4: 00 \mathrm{am}-5: 59 \mathrm{am}$ & 172 & 17 & 12.14 & 7.34 to 21.38 & 72 & 8 & 14.62 & 7.02 to 35.20 \\
\hline Total* & 6572 & 6528 & - & - & 4209 & 6357 & - & - \\
\hline
\end{tabular}

*Not included are 30 drivers with unknown time of crash and five drivers with unknown sex. $\mathrm{Cl}$, confidence interval. 
Table 3 Characteristics of visibly injured drivers, time of crash, and passenger presence

\begin{tabular}{|c|c|c|c|c|c|c|c|}
\hline Characteristic & Value & Controls & Cases & $\begin{array}{l}\text { Crude } \\
\text { odds ratio }\end{array}$ & $95 \% \mathrm{Cl}$ & $\begin{array}{l}\text { Adjusted } \\
\text { odds ratio* }\end{array}$ & $95 \% \mathrm{Cl}$ \\
\hline \multicolumn{8}{|l|}{ Driver and crash characteristics } \\
\hline \multirow[t]{2}{*}{ Driver age } & 16 & 4648 & 3963 & 1.27 & 1.20 to 1.34 & 1.37 & 1.29 to 1.45 \\
\hline & 17 & 7520 & 5061 & (ref) & - & (ref) & - \\
\hline \multirow[t]{2}{*}{ Driver sex } & Male & 6171 & 5396 & 1.45 & 1.37 to 1.53 & 1.25 & 1.18 to 1.33 \\
\hline & Female & 5997 & 3628 & (ref) & - & (ref) & - \\
\hline \multirow[t]{2}{*}{ Driver alcohol use } & Yes & 42 & 813 & 28.59 & 20.93 to 40.01 & 21.62 & 15.75 to 29.69 \\
\hline & No & 12126 & 8211 & (ref) & - & (ref) & - \\
\hline \multirow[t]{8}{*}{ Time of crash } & 4 pm-5:59 pm & 2079 & 1310 & 0.96 & 0.88 to 1.04 & 0.93 & 0.86 to 1.01 \\
\hline & $6 \mathrm{pm}-7: 59 \mathrm{pm}$ & 1632 & 1032 & 0.96 & 0.88 to 1.05 & 0.92 & 0.84 to 1.01 \\
\hline & 8 pm-9:59 pm & 1162 & 836 & 1.09 & 0.99 to 1.20 & 1.00 & 0.91 to 1.11 \\
\hline & 10 pm-11:59 pm & 770 & 820 & 1.62 & 1.45 to 1.80 & 1.30 & 1.16 to 1.46 \\
\hline & Midnight-1:59 pm & 279 & 529 & 2.88 & 2.47 to 3.35 & 1.86 & 1.58 to 2.19 \\
\hline & $2 \mathrm{am}-3: 59 \mathrm{am}$ & 89 & 274 & 4.67 & 3.65 to 6.02 & 2.78 & 2.14 to 3.61 \\
\hline & $4 \mathrm{am}-5: 59 \mathrm{am}$ & 25 & 182 & 11.05 & 7.23 to 17.55 & 9.29 & 6.02 to 14.34 \\
\hline & $6 \mathrm{am}-3: 59 \mathrm{pm}$ & 6132 & 4041 & (ref) & - & (ref) & - \\
\hline Passenger characteristics & No of passengers & & & & & & \\
\hline Driving alone & None & 5598 & 4449 & (ref) & - & - & - \\
\hline \multirow[t]{3}{*}{ Male teenage only } & 1 & 1337 & 1226 & 1.15 & 1.06 to 1.26 & 1.03 & 0.94 to 1.12 \\
\hline & 2 & 411 & 389 & 1.19 & 1.03 to 1.38 & 1.00 & 0.86 to 1.17 \\
\hline & 3 or more & 183 & 218 & 1.49 & 1.22 to 1.84 & 1.27 & 1.03 to 1.57 \\
\hline \multirow[t]{3}{*}{ Female teenage only } & 1 & 1533 & 969 & 0.80 & 0.73 to 0.87 & 0.85 & 0.77 to 0.93 \\
\hline & 2 & 388 & 235 & 0.76 & 0.64 to 0.90 & 0.79 & 0.67 to 0.94 \\
\hline & 3 or more & 166 & 91 & 0.69 & 0.53 to 0.90 & 0.69 & 0.53 to 0.90 \\
\hline \multirow[t]{2}{*}{ Mix of male and female teenage } & 2 & 299 & 238 & 1.00 & 0.84 to 1.20 & 0.96 & 0.80 to 1.15 \\
\hline & 3 or more & 341 & 364 & 1.34 & 1.15 to 1.57 & 1.20 & 1.03 to 1.41 \\
\hline \multirow[t]{2}{*}{ Young adult (ages 20-29) } & 1 & 256 & 164 & 0.81 & 0.66 to 0.99 & 0.71 & 0.57 to 0.88 \\
\hline & 2 or more & 29 & 13 & 0.56 & 0.27 to 1.12 & 0.31 & 0.14 to 0.67 \\
\hline \multirow[t]{2}{*}{ Mature adult (ages $30+$ ) } & 1 & 521 & 128 & 0.31 & 0.25 to 0.38 & 0.30 & 0.25 to 0.37 \\
\hline & 2 or more & 51 & 9 & 0.22 & 0.10 to 0.46 & 0.22 & 0.11 to 0.46 \\
\hline Mix of young and mature adult & 2 or more & 24 & 5 & 0.26 & 0.08 to 0.70 & 0.25 & 0.09 to 0.67 \\
\hline \multirow[t]{2}{*}{ Children only } & 1 & 209 & 108 & 0.65 & 0.51 to 0.83 & 0.71 & 0.56 to 0.91 \\
\hline & 2 or more & 59 & 36 & 0.77 & 0.49 to 1.18 & 0.90 & 0.59 to 1.38 \\
\hline \multirow[t]{2}{*}{ Mix of teen and adults } & 2 & 190 & 97 & 0.64 & 0.50 to 0.83 & 0.57 & 0.44 to 0.74 \\
\hline & 3 or more & 151 & 101 & 0.84 & 0.65 to 1.09 & 0.57 & 0.43 to 0.76 \\
\hline \multirow[t]{2}{*}{ Mix of teen and children } & 2 & 124 & 66 & 0.67 & 0.49 to 0.91 & 0.75 & 0.55 to 1.02 \\
\hline & 3 or more & 97 & 71 & 0.92 & 0.67 to 1.27 & 0.95 & 0.70 to 1.31 \\
\hline Other mix & 2 or more & 201 & 47 & 0.28 & 0.16 to 0.46 & 0.31 & 0.22 to 0.43 \\
\hline Total & - & 12168 & 9024 & - & - & - & - \\
\hline
\end{tabular}

occurred on the weekend (Friday to Sunday) than control crashes $(47 \% \vee 44 \%)$.

Driver alcohol use was markedly more prevalent among cases. Ten percent of case drivers were identified as having used alcohol, while only $0.3 \%$ of controls were identified as such.

Overall, $54 \%$ of young drivers were carrying passengers at the time of crash. Cases were more likely to be carrying two or more passengers than controls and less likely to be carrying only one passenger.

Relative to daytime driving ( 6 am to $7: 59 \mathrm{pm}$ ), both males and females were at higher risk of crash between the hours of $8 \mathrm{pm}$ and 5:59 am (table 2). There appears to be little or no elevation of risk during the hours of $4 \mathrm{pm}$ to $10 \mathrm{pm}$, but after $10 \mathrm{pm}$ risk increases with advancing nighttime hours. Male drivers experienced a larger increase in crash risk during night time categories than female drivers.
For visibly injured drivers (table 3), being 16 (adjusted odds ratio $(\mathrm{ORa})=1.37)$ and male $(\mathrm{ORa}=1.25)$ were each associated with increased crash risk. Alcohol use was most strongly associated with crash risk (ORa $=21.62)$. The rate of crash increased with advancing night hours. Overall, adjusted odds ratios for nighttime periods were slightly less than crude odds ratios. Relative to driving alone, young drivers who were carrying male teenage passengers were at a slightly higher risk of crash, while those carrying female teenagers, children, or adults were at a lower risk of crash. Carrying young adults was slightly more protective than carrying female teenagers or children. Carrying mature adults was the most protective of all passenger combinations. For example, the rate of crash was $70 \%$ lower when carrying one mature adult, compared with driving alone.

Table 4 gives crude and adjusted odds ratios for severely or fatally injured drivers' crash involvements. As in the case of 
Table 4 Characteristics of severely or fatally injured drivers, time of crash, and passenger presence

\begin{tabular}{|c|c|c|c|c|c|c|c|}
\hline Characteristic & Value & Controls & Cases & $\begin{array}{l}\text { Crude } \\
\text { odds ratio }\end{array}$ & $95 \% \mathrm{Cl}$ & $\begin{array}{l}\text { Adjusted } \\
\text { odds ratio* }\end{array}$ & $95 \% \mathrm{Cl}$ \\
\hline \multicolumn{8}{|l|}{ Driver and crash characteristics } \\
\hline \multirow[t]{2}{*}{ Driver age } & 16 & 4648 & 405 & 1.13 & 0.99 to 1.29 & 1.25 & 1.08 to 1.45 \\
\hline & 17 & 7520 & 581 & (ref) & - & (ref) & - \\
\hline \multirow[t]{2}{*}{ Driver sex } & Male & 6171 & 634 & 1.75 & 1.53 to 2.01 & 1.37 & 1.18 to 1.60 \\
\hline & Female & 5997 & 352 & (ref) & - & (ref) & - \\
\hline \multirow[t]{2}{*}{ Driver alcohol use } & Yes & 42 & 184 & 66.24 & 46.71 to 95.61 & 39.77 & 27.69 to 57.12 \\
\hline & No & 12126 & 802 & (ref) & - & (ref) & - \\
\hline \multirow[t]{8}{*}{ Time of crash } & 4 pm-5:59 pm & 2079 & 102 & 0.80 & 0.64 to 1.01 & 0.80 & 0.63 to 1.00 \\
\hline & $6 \mathrm{pm}-7: 59 \mathrm{pm}$ & 1632 & 125 & 1.26 & 1.01 to 1.55 & 1.15 & 0.92 to 1.43 \\
\hline & 8 pm-9:59 pm & 1162 & 96 & 1.35 & 1.06 to 1.72 & 1.11 & 0.87 to 1.43 \\
\hline & 10 pm-11:59 pm & 770 & 120 & 2.56 & 2.03 to 3.19 & 1.84 & 1.45 to 2.35 \\
\hline & Midnight-1:59 pm & 279 & 90 & 5.29 & 4.03 to 6.89 & 2.47 & 1.79 to 3.42 \\
\hline & 2 am-3:59 am & 89 & 51 & 9.40 & 6.41 to 13.63 & 3.70 & 2.34 to 5.87 \\
\hline & $4 a m-5: 59$ am & 25 & 28 & 18.36 & 10.20 to 33.15 & 10.63 & 5.55 to 20.32 \\
\hline & $6 \mathrm{am}-3: 59 \mathrm{pm}$ & 6132 & 374 & (ref) & - & (ref) & - \\
\hline Passenger characteristics & No of passengers & & & & & & \\
\hline Driving alone & None & 5598 & 413 & (ref) & - & (ref) & - \\
\hline \multirow[t]{3}{*}{ Male teenage only } & 1 & 1337 & 165 & 1.67 & 1.38 to 2.03 & 1.45 & 1.18 to 1.79 \\
\hline & 2 & 411 & 51 & 1.68 & 1.21 to 2.30 & 1.17 & 0.82 to 1.68 \\
\hline & 3 or more & 183 & 32 & 2.37 & 1.55 to 3.52 & 1.74 & 1.12 to 2.69 \\
\hline \multirow[t]{3}{*}{ Female teenage only } & 1 & 1533 & 97 & 0.86 & 0.68 to 1.08 & 0.92 & 0.72 to 1.17 \\
\hline & 2 & 388 & 31 & 1.08 & 0.72 to 1.59 & 1.16 & 0.78 to 1.74 \\
\hline & 3 or more & 166 & 10 & 0.82 & 0.38 to 1.56 & 0.84 & 0.42 to 1.67 \\
\hline \multirow[t]{2}{*}{ Mix of male and female teenage } & 2 & 299 & 22 & 1.00 & 0.61 to 1.56 & 1.01 & 0.63 to 1.60 \\
\hline & 3 or more & 341 & 53 & 2.11 & 1.52 to 2.87 & 1.82 & 1.30 to 2.54 \\
\hline Young adult (ages 20-29) & 1 or more & 285 & 37 & 1.76 & 1.20 to 2.53 & 1.34 & 0.89 to 2.03 \\
\hline Mature adult (ages $30+$ ) & 1 or more & 572 & 11 & 0.26 & 0.13 to 0.48 & 0.28 & 0.15 to 0.53 \\
\hline Mix of young and mature adult & 2 or more & 24 & 0 & - & - & - & - \\
\hline Children only & 1 or more & 268 & 12 & 0.61 & 0.31 to 1.09 & 0.81 & 0.45 to 1.47 \\
\hline \multirow[t]{2}{*}{ Mix of teen and adults } & 2 & 190 & 13 & 0.93 & 0.48 to 1.64 & 0.60 & 0.30 to 1.19 \\
\hline & 3 or more & 151 & 19 & 1.71 & 0.99 to 2.79 & 1.00 & 0.56 to 1.79 \\
\hline Mix of teen and children & 2 or more & 221 & 11 & 0.67 & 0.33 to 1.24 & 0.86 & 0.46 to 1.59 \\
\hline Other mix & 2 or more & 201 & 9 & 0.61 & 0.27 to 1.19 & - & - \\
\hline Total & - & 12168 & 986 & - & - & - & - \\
\hline
\end{tabular}

visibly injured drivers, increased crash rates were associated with being $16(\mathrm{ORa}=1.37)$, being male $(\mathrm{ORa}=1.25)$, and nighttime driving (ORa for driving in time categories $10 \mathrm{pm}$ to midnight, midnight to $2 \mathrm{am}, 2$ am to $4 \mathrm{am}$, and 4 am to 6 am were $1.84,2.47,3.70$, and 10.63 , respectively). Drivers identified as having used alcohol were 40 times more likely to be involved in a crash that severely or fatally injured the driver (95\% confidence interval 27.7 to 57.1 ). Carrying any number of young male passengers or three or more young passengers of mixed gender increased the crash risk, while carrying only young female passengers had no effect on crash risk. Carrying young adults appears to have increased crash risk slightly $($ ORa $=1.34)$, while carrying mature adults was associated with a greatly reduced crash risk $(\mathrm{ORa}=0.28)$. Too few crashes occurred when a driver was carrying children or combinations of children, teenagers, or adults for precise risk ratios to be estimated.

\section{DISCUSSION}

It has long been observed that nighttime driving is particularly risky for young drivers. For example, Williams reports that the per mile fatal crash rate of 16 year old male drivers is four times greater at night than during the day. ${ }^{27}$ Nighttime crashes are a problem for young drivers for a variety of reasons. Teenagers often engage in risk taking behaviors at night ${ }^{28}$ and may less often be adult supervised. It has also been noted that while teenagers drive less than adults, they do a larger share of their driving at night. Given the differences in daytime and nighttime crash occurrence and outcomes, it is not surprising that nighttime curfews and graduated licensing systems that restrict nighttime driving have been effective in reducing crash occurrence. ${ }^{29-35}$

In this report we attempt to clarify how nighttime driving and the presence of passengers of various ages influence injury crash rates. Our data support many of the findings of earlier risk factor studies in that both nighttime driving and passenger carrying were strongly associated with increased crash rates. The likelihood of causing an injury crash increased with advancing late night hours for both male and female teenagers. Rate ratios ranged from 1.3 to 10.6. The hours of 10 pm to midnight are particularly dangerous for teenager drivers, despite having lower rate ratios than later time periods. A 
greater number of drivers were critically injured between 10 pm and midnight than during any other two hour late night time interval. Several other studies have also identified the 10 pm to midnight time period as risky for teenage drivers, yet only six of the 39 graduated licensing systems in the US have restrictions in effect during all of this time period. ${ }^{5}$

Relatively few studies of the effects of carrying passengers appear in the literature. Most have reported a fairly strong effect of passenger carrying on crash incidence. The risk of fatal crash involvement may be elevated when young drivers carry passengers for several reasons. One reason is that the crashes may differ with respect to driver behavior or crash circumstances (for example, speed of driving, road type). A second reason is that higher vehicle occupancy increases the opportunity for fatal injury. Studies that examine fatal crash involvements will detect changes in rates that are attributable to changes in occupancy as well as changes in driver behavior. For example, Preusser et al report that the risk of at-fault fatal crash involvement is higher among young drivers carrying passengers than those traveling alone. ${ }^{9}$ In their study, fatal crashes were defined as a crash in which any person was killed. Thus the reported rate increase reflects changes in occupancy and may (or may not) reflect changes in driver behaviors or crash circumstances.

In this report, to better understand the effect of passengers independent of the increase in vehicle occupancy, we used driver injury as the outcome of interest. A multivariate model allowed us to control for confounding by other risk factors like time of day and alcohol use. We allowed the passenger rate ratios (estimated with odds ratios) to vary across levels of time category and alcohol use and found that there was no meaningful or statistically significant rate ratio heterogeneity. When young drivers carry passengers, the rates increased to the same degree (on a multiplicative scale) during daytime and nighttime hours and for drinking and non-drinking drivers.

A primary finding of this analysis is that driving in the absence of adult supervision is strongly associated with an increased crash rate. We found that teenagers driving alone were much more likely to cause crashes than those driving in the presence of an adult 30 or older, and those carrying teenage passengers were notably more likely to cause crashes than those driving alone. While driving under adult supervision is markedly safer than driving alone or with young passengers, it should be noted that it appears to be quite uncommon. Among the control drivers, only 7\% were carrying one or more mature adults 30 or older. Because of the high prevalence of unsupervised driving, disincentives to driving without an adult may produce significant reductions in crashes.

Although alcohol use was uncommon $(0.3 \%$ among the control drivers ), drinking drivers were markedly more likely to be involved in visible and severe/fatal driver injury crashes (ORa $=21.6$ and 39.8, respectively). The low proportion of drinking drivers may be related to California's zero tolerance law for persons under age 21 , which prohibits driving with a blood alcohol concentration of $0.01 \%$ or greater. Every state in the US currently has a similar zero tolerance law, ${ }^{36}$ so few graduated licensing systems in the US specifically address drinking and driving. Licensing jurisdictions outside the US may benefit from the inclusion of an alcohol specific restriction in graduated systems or the use of both legislative approaches together.

This study has several limitations. Rate ratio estimates for driver alcohol use could be biased if the presence of alcohol influenced the determination of culpability by the reporting police officer independently of the effect of alcohol use and other factors on the "true" culpability status. However, we expect that overt signs of alcohol use would have a rather small influence on culpability determination (holding all other factors constant), and thus any resulting bias should be inconsequential. An officer's determination of culpability may

\section{Key points}

- The lack of adult supervision, the presence of "young" passengers, and driving at night are strongly associated with increased injury crash rates among 16 and 17 year old drivers.

- Driving restrictions that begin at $10 \mathrm{pm}$ may be more effective than restrictions that begin at a later hour.

- Restrictions on carrying passengers at all hours may reduce the occurrence of injury crashes.

- Encouraging adult supervised driving may further reduce crash rates.

be influenced by other factors like crash severity, time of crash, driver sex, and passenger presence, and this may have biased results. Finally, to the extent that the controls do not represent the actual exposure to driving risk by young drivers in California, the estimated rate ratios will be biased from the true parameters. The direction and magnitude of these possible biases are unknown.

\section{IMPLICATIONS FOR PREVENTION}

Only $22(56 \%)$ of the graduated licensing systems in the US restrict the carrying of passengers. This report and other studies indicate that the presence of young passengers leads to higher rates of motor vehicle crashes. The incorporation of passenger restrictions into existing graduated systems should result in fewer severe and fatal injuries by reducing the number of at-risk vehicle occupants and by reducing driver behaviors that are associated with high crash rates. However, if the restrictions lead to additional motor vehicle trips by individual teenagers the overall safety benefit could be less than expected. (Research has shown that a notable safety benefit would be obtained under any one of a variety of realistic compliance scenarios. ${ }^{37}$ ) In addition, passenger restrictions that are in effect at all hours should lead to larger reductions of injuries than those in effect only at night or only on certain days of the week.

This analysis found that driving in the absence of adult supervision with or without passengers leads to a much higher risk of crash than adult supervised driving. Modifying graduated licensing systems so that initial stages of licensure allow only adult supervised driving may improve their effectiveness.

Twelve US states issue traditional licenses to teenagers that allow them immediate access to unsupervised driving at all hours. The rate of crash involvement by young drivers may be reduced if these states adopt restrictions on driving between $10 \mathrm{pm}$ and $6 \mathrm{am}$. The hours of $10 \mathrm{pm}$ to midnight are especially risky for young drivers in terms of crash incidence and driver injury severity. States with nighttime driving restrictions could reduce the number of critical injuries to drivers and their passengers by expanding the restrictions to include these hours.

\section{ACKNOWLEDGEMENT}

The authors are grateful to the California Highway Patrol for supplying the data used in this study, and to Craig L Anderson for his helpful comments on an earlier draft of the manuscript. This work was supported by grant No R49/CCR903622 to the Southern California Injury Prevention Research Center from the US Centers for Disease Control and Prevention.

\section{Authors' affiliations}

T M Rice, C Peek-Asa, J F Kraus, Southern California Injury Prevention Research Center, University of California, Los Angeles, School of Public Health 


\section{REFERENCES}

Soliday SM. Relationship between age and hazard perception in automobile drivers. Percept Mot Skills 1974;39:335-8.

2 Deery HA. Hazard and risk perception among young novice drivers. J Safety Res 1999;30:225-36.

3 Wasielewski P. Speed as a measure of driver risk: observed speed versus driver and vehicle characteristics. Accid Anal Prev 1984; 16:89-103.

4 Evans L, Wasielewski P. Risky driving related to driver and vehicle characteristics. Accid Anal Prev 1983;15:121-36.

5 Insurance Institute for Highway Safety. US licensing systems for young driver. Arlington, VA: Insurance Institute for Highway Safety, April 2003 .

6 Robertson L. Patterns of teenaged driver involvement in fatal motor vehicle crashes: implications for policy choice. J Polit Policy Law 1981;6:303-14.

7 Williams AF, Preusser DF, Ulmer RG, et al. Characteristics of fatal crashes of 16-year-old drivers: implications for licensure policies. J Public Health Policy 1995; 16:347-60.

8 Doherty ST, Andrey JC, MacGregor C. The situational risks of young drivers: the influence of passengers, time of day and day of week on accident rates. Accid Anal Prev 1998;30:45-52.

9 Preusser DF, Ferguson SA, Williams AF. The effect of teenage passengers on the fatal crash risk of teenage drivers. Accid Anal Prev 1998;30:217-22

10 Aldridge B, Himmler M, Aultman-Hall L, et al. Impact of passengers on young driver safety. Transportation Research Record 1999:1999:25-30.

11 Chen LH, Baker SP, Braver ER, et al. Carrying passengers as a risk factor for crashes fatal to 16 - and 17 -year-old drivers. JAMA 2000;283: 1578-82.

12 Williams AF. Teenage passengers in motor vehicle crashes: a summary of current research. Arlington, VA: Insurance Institute for Highway Safety, 2001.

13 Cuthbert JR. An extension of the induced exposure method of estimating driver risk. J R Statist Soc A 1994;157:177-90.

14 Thorpe JD. Calculating relative involvement rates in accidents without determining exposure. Aust Road Res 1964;2:25-36.

15 Carr BR. A statistical analysis of rural Ontario traffic accidents using induced exposure data. Accid Anal Prev 1969;1:434-57.

16 Haight FA. A crude framework for bypassing exposure. J Safety Res 1970;2:26-9.

17 DeYoung DJ, Peck RC, Helander CJ. Estimating the exposure and fatal crash rates of suspended/revoked and unlicensed drivers in California. Accid Anal Prev 1997;29:17-23.

18 Aldridge B, Himmler M, Aultmann-Hall L, et al. Impact of passengers on driver safety. Transportation Research Record 1999;1693:25-30.
19 Rothman KJ, Greenland S. Modern epidemiology. 2nd Ed. Philadelphia: Lippincott-Raven, 1998.

20 Lilienfeld AM, Lilienfeld DE. A century of case-control studies: progress? J Chronic Dis 1979;32:5-13

21 Cornfield J. A method of estimating comparative rates from clinical data. Applications to cancer of the lung, breast, and cervix. J Nat Cancer Inst 1951;11:1269-75.

22 Woolf B. On estimating the relation between blood group and disease. Ann Hum Genet 1954:19:251-3.

23 Mantel N, Haenszel W. Statistical aspects of the analysis of data from retrospective studies of disease. I Nat Cancer Inst 1959.22.719-48.

24 Greenland S, Thomas DC. On the need for the rare disease assumption in case-control studies. Am J Epidemiol 1982;116:547-53.

25 Greenland S, Thomas DC, Morgenstern H. The rare-disease assumption revisited. A critique of "estimators of relative risk for case-contro studies". Am J Epidemiol 1986;124:869-83.

26 Kraus JF, Morgenstern H, Fife D, et al. Blood alcohol tests, prevalence of involvement, and outcomes following brain injury. Am J Public Health 1995:79:294-9.

27 Williams AF. Nighttime driving and fatal crash involvement of teenagers. Accid Anal Prev 1985;17:1-5.

28 Farrow JA. Young driver risk taking: a description of dangerous driving situations among 16- to 19-year-old drivers. Int J Addict 1987;22:1255-67.

29 Preusser DF, Zador PL, Williams AF. The effect of city curfew ordinances on teenage motor vehicle fatalities. Accid Anal Prev 1993;25:641-5.

30 Langley JD, Wagenaar AC, Begg DJ. An evaluation of the New Zealand graduated driver licensing system. Accid Anal Prev Zealand graduated

31 Boase P, Tasca L. Graduated licensing system evaluation: interim report '98. Ontario, Canada: Ministry of Transportation, 1998.

32 Mayhew DR, Simpson HM, des Groseillers M, et al. Impact of the graduated driver licensing program in Nova Scotia. J Crash Prev 2001;2:179-92.

33 Ulmer JD, Preusser DF, Williams AF, et al. Effects of Florida's graduated licensing program on the crash rate of teenage drivers. Accid Anal Prev 2000;32:527-32

34 Foss RD, Feaganes JR, Rodgman EA. Initial effects of graduated driver licensing on 16-year-old driver crashes in North Carolina. JAMA 2001;286: 1588-92.

35 Shope JT, Molnar L, Elliot MR, et al. Graduated driver licensing in Michigan: early impact on motor vehicle crashes among 16-year-old drivers. JAMA 2001;286:1593-58

36 Insurance Institute for Highway Safety. Status Report 2000;35:7

37 Chen LH, Baker SP, Braver ER, et al. Potential benefits of restrictions on the transport of teenage passengers by 16 and 17 year old drivers. In Prev 2001;33:129-34. 